\title{
Circle Economy in Mining Industry-Hydraulic Backfill Use in Velenje Coal Mine
}

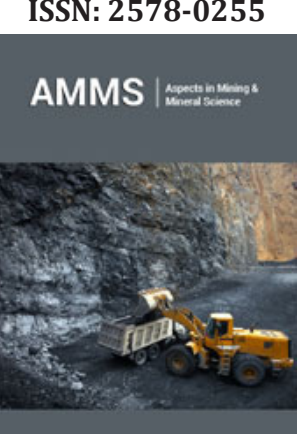

*Corresponding author: Jože Kortnik, University of Ljubljana, Faculty of Natural Sciences and Engineering, Department of Geotechnology, Mining and Environment, Ljubljana, Slovenia

Submission: 制 December 01, 2020

Published: 䘜January 18, 2021

Volume 6 - Issue 1

How to cite this article: Jože Kortnik, Circle Economy in Mining IndustryHydraulic Backfill Use in Velenje Coal Mine. Aspects Min Miner Sci. 6(1). AMMS 000628. 2021.

DOI: 10.31031/AMMS.2021.06.000628

Copyright@ Jože Kortnik, This article is distributed under the terms of the Creative Commons Attribution 4.0 International License, which permits unrestricted use and redistribution provided that the original author and source are credited.

\section{Jože Kortnik*}

Faculty of Natural Sciences and Engineering, Departmentof Geotechnology, Mining and Environment, Slovenia

\section{Abstract}

Adverse impacts on human environment are growing daily. Possible new locations for mining activities in Slovenia and worldwide are becoming very scarce. Particularly sensitive issue usually is to find appropriate location for disposal of mining waste, generated by process of excavation and processing/transformation of metal/non-metal minerals and coal. By establishing of closed ecological and technological circle of winning, processing or energy transformation and returning mining waste materials into excavated open space it is possible to organize environment friendly, sustainable metal/nonmetal/coal mining or circle economy in mining industry. By depositing mining waste into underground space, earth surface can be disburdened. Suitable location should take existing natural barriers into account otherwise technical measures have to be taken to protect surrounding formation against adverse impact. Essential conditions for underground mining and processing or transformation mining waste depositing is reliable and durable protection against spreading of adverse impact of deposited waste materials into surroundings, particularly in hydrosphere. For this, natural and/or technical barriers should be thoroughly used. The good results of this research should assure by selection of appropriate waste materials mixtures preparation, transport and deposition by proper technology, future mining to be ecologically sustainable/green and economically effective. A brief outline of backfilling by thick suspension mixtures performed in Velenje coal mine will be presented.

Keywords: Circle economy;Hydraulic backfill; Velenje coal mine

\section{Introduction}

The perspective of coal mining in the Slovenia and in the world is mainly related to the introduction of environmentally friendly technologies for coal mining and conversion into electricity. Given the fact that the content of ash and free sulfur in Slovenian coal is relatively high, it is necessary to take appropriate care of the products of combustion and flue gas cleaning during energy conversion in the Šoštanj thermal power plant. Use or. the return of large quantities of waste materials generated during the extraction and conversion of coal into electricity in excavated cave spaces significantly reduces the impact of excavation on the surface, improves the stress-strain state in the rock around the excavation and at the same time eliminates the surface landfills [1]. We are talking about the quantities of several millions $\mathrm{m}^{3}$ of secondary waste materials that still need to be transported from the place of origin of the thermal power plant to the place of disposal of the excavated underground spaces [2]. The connected operation of a coal mine and a thermal power plant, with the return of secondary waste materials (Directive 2006/21/EC) into open underground spaces, we can call a closed ecological-technological cycle of electricity production or circular management of electricity production (EU Directive 2018/851) or environmentally friendly/green extraction of coal and its conversion into electricity. In the process of circular management in electricity production, the following negative impacts on the environment occur $[3,4]$ :

\section{In the phase of extraction}
a. Change in the primary stress state in the rock,
b. Deformations as a result of demolition processes,
c. Deposition of pit tailings on the surface.

\section{In the phase of mineral processing}
a. Disposal of separation tailings on the surface,
b. Disposal of separation sludge on the surface, 
c. Discharge of technological water into the environment.

\section{In the phase of conversion of coal into electricity}

a. Disposal of slag, gypsum, ash and fly ash,

b. Emissions of flue gases into the environment $\left(\mathrm{SO}_{2}, \mathrm{NO}_{\mathrm{x}^{\prime}}\right.$ $\left.\mathrm{CO}_{2}\right)$.

Taking into account the principle of waste management, that each waste producer must ensure the proper treatment of waste alone or with an officially recognized contractor (Directive 2008/98/EC or EU Directive 2018/851), the mining (coal extraction) industry has the advantage, that it can use the excavated open spaces for the disposal of practically all secondary waste materials generated in the process of extraction and energy conversion of coal into electricity, as well as secondary waste materials of other industries, as you can see in Figure 1. In this respect, the connection of the coal mine and the thermal power plant into an ecologicallytechnologically closed cycle of electricity production or circular management in the production of electricity is an optimal solution. With the introduction of ecologically-technologically closed cycle of electricity production or circular management in the production of electricity, we gain many advantages, such as [4]:

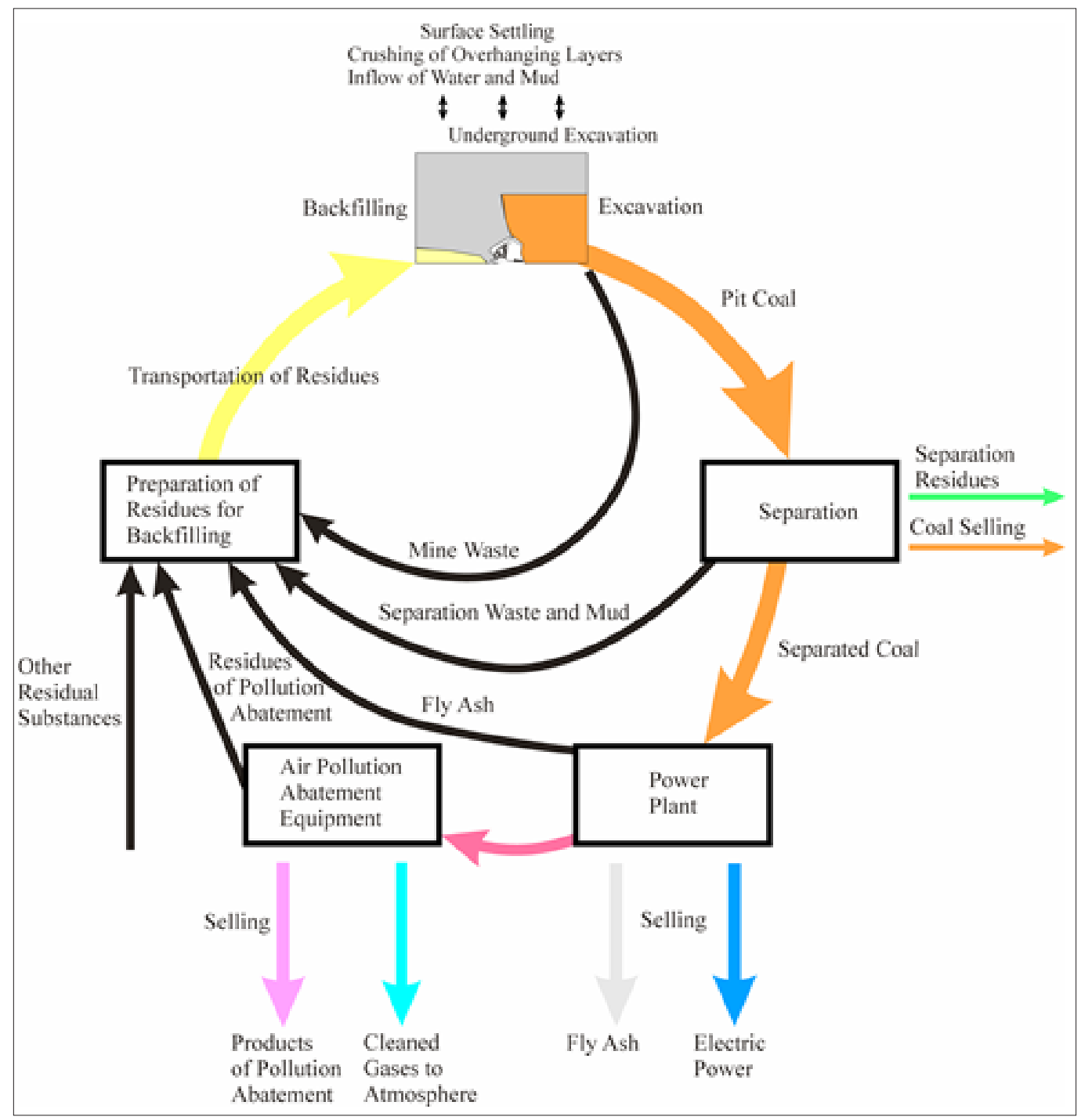

Figure 1: Ecologically-technologically closed cycle of electricity production or circular economy in the production of electricity from coal in Velenje coal mine [3,4].

a. reduction of coal excavation losses,

b. higher quality or calorific value of extracted coal,

c. increasing productivity at excavations and in the preparation of preparatory lines, d. reduction of maintenance costs of cave facilities,

e. reduction of the possibility of the collapse of hanging wall and the intrusion of water, sludge or liquid sands,

f. smaller settlements on the surface, 
g. Avoid the construction of surface landfills for cave and separation tailings, ash, EF ash and gypsum, flue gas cleaning products.

These advantages can be achieved that the excavated open spaces (goaf area) are filled with backfill mixtures of appropriate physical and mechanical properties. The technology of preparation, transport and installation of backfill mixtures must meet the technological requirements of coal extraction.

\section{Development of Backfilling in Velenje Coal Mine}

At the Velenje Coal Mine exploits the coal seam, with a calorific value of $8.4-10.5 \mathrm{MJ} / \mathrm{kg}$, in the form of an elongated lens, $8.3 \mathrm{~km}$ long, $2.5 \mathrm{~km}$ wide and with a maximum thickness of $170 \mathrm{~m}$ at a depth of 200 to $500 \mathrm{~m}$, with the beginning of exploitation in 1875 (145 ${ }^{\text {th }}$ anniversary) [1]. The excavation technology was developed through simple excavation methods to a high-performance Velenje long wall mining method (average production 4 million t/year) with today's mechanized extraction method (hydraulic shield support with electro-hydraulic control, two-drum cutting extraction machine, front chain conveyor frequency and directional, etc.), the possibility of vertical and horizontal concentration of excavations and the possibility of backfilling of the excavated space behind the stope. At the Velenje Coal Mine, backfilling was carried out intensively mainly in the period of years 1992-2004 at stopes k.+157, B/5b, B/6, B/6b in the Škale mine, stope D k.+25 in the Pesje mine, at stope L2 and stopes G1/A, G1/B and G1/C in the north-western part of the Preloge mine (Gaberka excavation field). A schematic representation of the backfilling of the goaf area of the stope with the backfill mixture is shown on Figure 2. It was found that the construction of new level excavation roads under areas backfilled with backfill mixtures (pastas) is significantly safer, and with the use of lighter support measures also faster, mainly due to improved geotechnical conditions by backfilling the hardened rock. Furthermore, it was found also that the disturbed coal seam hardened with embossed backfill mixture can represent a technical solution to improve geotechnical conditions in continuing coal mining on lower levels towards the seam floor-wall and also in preventing oxidation processes of coal in stope safety pillars during excavations on the level.

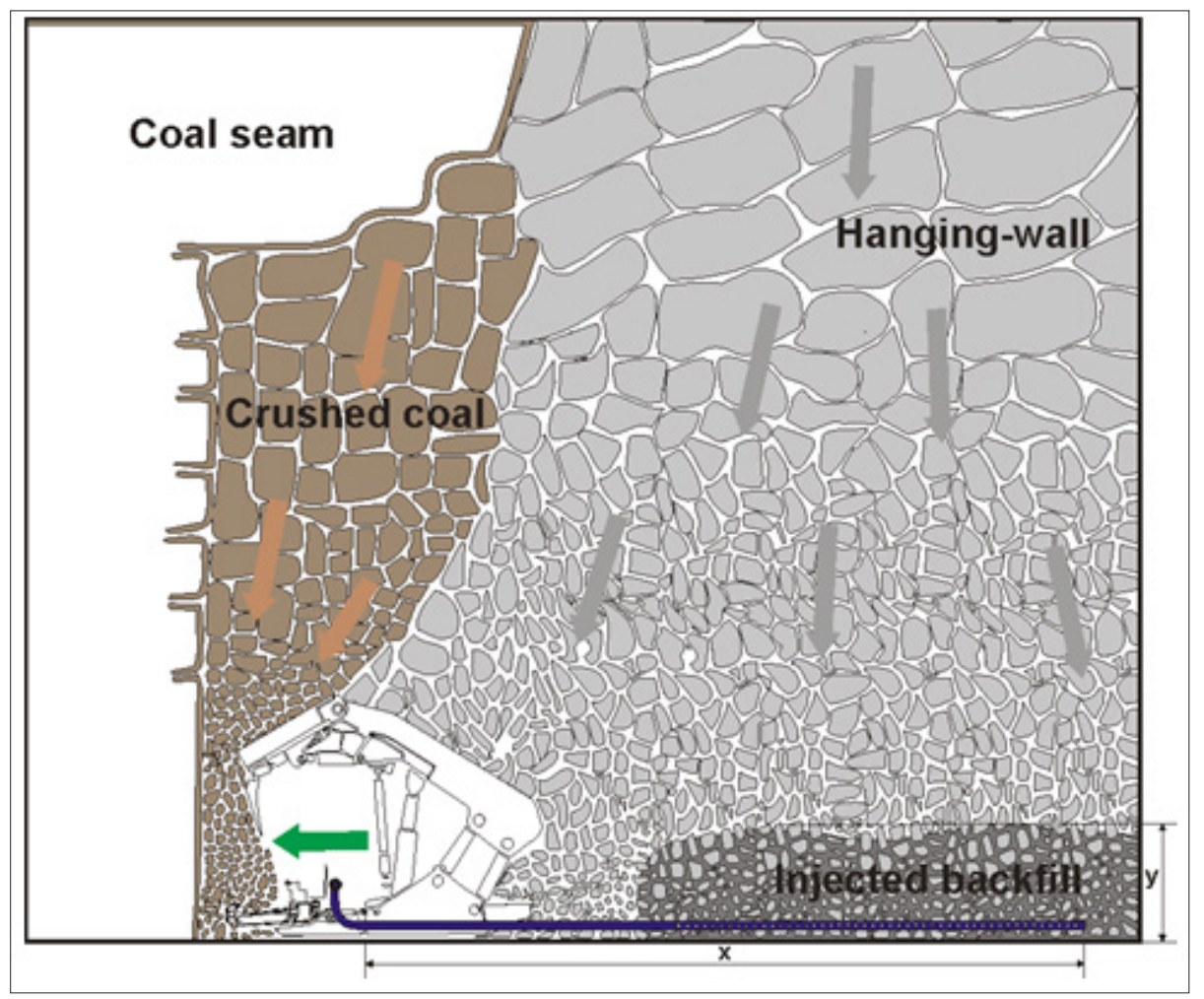

Figure 2: Schematic representation of backfilling the goaf area of the stope with the backfill mixture (pasta) in Velenje coal mine [2].

The backfill mixtures recipes were adapted to the transport conditions, the requirements for installation into the old excavation work, the achievement of the required final geomechanically characteristics and the impact of the eluates on the environment, especially the hydrosphere. The backfill mixtures were made of various materials such as EF ash, cement, lime, bentonite, and various additives to inhibit and accelerate setting. The purpose of filling after excavation was mainly in:

a. consolidation of the excavated old part after excavation and improvement of geotechnical conditions in the construction of lower-lying floor excavation lines, 
b. prevention of oxidation processes in coal in safety columns during excavations on the floor,

c. construction of an indicative backfill to control the excavation height on the lower floor,

d. return of secondary materials (fly ash, gypsum, secondary materials of industry) to open underground areas,

The backfilling technology used on stope B/5b in the Škale mine first consisted mainly of three main phases: the phase of backfilling mixtures preparation in the surface mixing station, the phase of hydraulic transport of the backfill mixture by pipeline to the stope and the phase of backfill mixture injection into the goaf area [3].
The achieved results of backfilling the goaf areas of stopes B5/b and $\mathrm{B} 6 / \mathrm{b}$ are collected in (Table $1 \&$ Figure 3 ) graphically shows the heights of the injected backfill mixtures into the goaf area of stope B5/b. The backfilling technology used on stope D k.+25 in Pesje mine, on stope L2 and stopes G1/A and G1/B in the north-western part of Preloge mine was consists of five main phases such as the phase of liquid backfill mixture preparation in the surface mixing station, the phase of liquid backfill hydraulic transportation by pipeline to the underground mixing station, the phase of preparation of the thick backfill mixture in the underground mixing station, the phase of hydraulic transport of the thick backfill mixture by pipeline to the stope and the phase of thick backfill mixture injection into the goaf area after stope $[5,6]$.

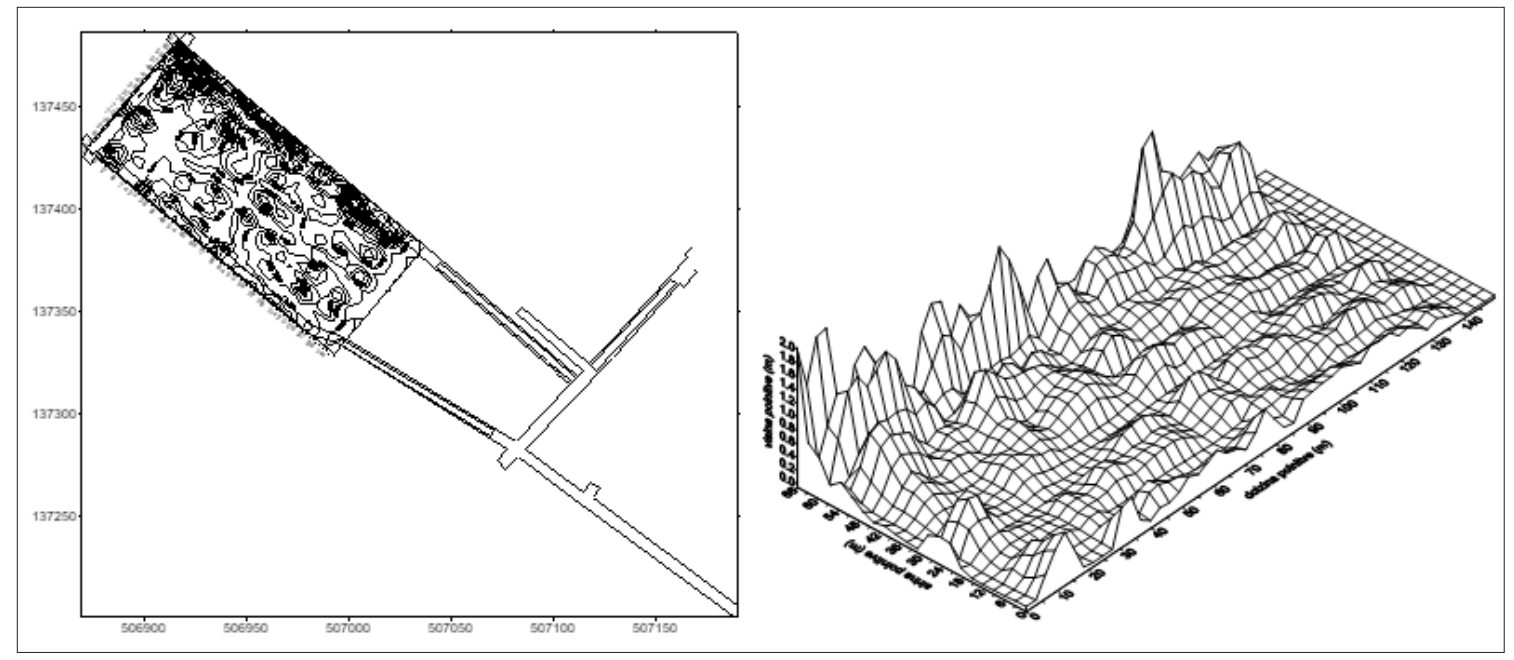

Figure 3: Graphic representation of the backfilling over the entire width of the stope B5/b with backfill mixture-paste [3].

Table 1: Achieved parameters of backfilling with backfill mixtures (pastes) on stopes B5/b, B6/b, G1/A and G1/B.

\begin{tabular}{|c|c|c|c|c|}
\hline Stope & B5/b & B6/b & G1/A & G1/B \\
\hline Injected paste quantity $\left(\mathrm{m}^{3}\right)$ & 947 & 2,389 & 3,606 & 2,097 \\
\hline Max. injected heigh $\left(\mathrm{cm} / \mathrm{m}^{2}\right)^{*}$ & 24 & 65 & 70 & 51 \\
\hline Averg. injected height $\left(\mathrm{cm} / \mathrm{m}^{2}\right)$ & 19 & 25 & 38 & 30 \\
\hline
\end{tabular}

\section{Conclusion}

Mining methods with backfill enable the introduction of Circular economy or closed Ecological-Technological circle and thus Environmentally friendly or Green mining of mineral resources. This means that various waste materials generated during the extraction and processing of mineral raw materials are used for the preparation of backfill mixtures for filling and consolidation of open underground spaces, and at the same time we reduce the quantities of these substances deposited in surface landfills. In addition, some secondary industrial waste materials can be also used to achieve the required properties of backfill mixtures, in doing so, we are obliged to observe the principles of environmental protection. The basis of all backfill mixtures used at Premogovnik Velenje is fly ash from the nearby Šoštanj Thermal Power Plant, to which we add various additives and secondary materials of industry to ensure stability. The suitability of backfill mixtures is determined on the basis of investigations of the physical and chemical properties individual backfill components as well as whole backfill mixtures. The technical, economic and other aspects of the hydraulic transportation of thick backfill mixtures (pastes) may be estimated only if the rheological properties of flowing backfill suspensions (pastes) are previously determined. For this purpose we developed the ball pull test, tube viscosimeter and pressure leaching test. The use of these test tools enables the continuation of the introduction of mining methods with backfill and thus ensuring a greater competitive advantage of the Slovenian mining industry. 


\section{References}

1. Velenje Coal mine, Slovenia.

2. Bajželj U, Medved M, Oprešnik B, Kortnik J, Likar J (1994) The return of waste materials into active mines. $2^{\text {nd }}$ International Conference on the Construction of Tunnels and Underground Spaces, Ljubljana, Slovenia. p. 20.

3. Bajželj U, Medved M, Oprešnik B, Jenko B, Križan J (1994) Automatization of the technological process of injecting paste made of fly ash into the goafs in the Velenje lignite mine. APCOM, Bled, Slovenia. p. 13.
4. Bajželj U, Likar J, Medved M, Oprešnik B, Kortnik J (1995) Preparation and purpose of using ash traps and technology of pressing into destroyed excavated spaces. Mining Consultation at the $34^{\text {th }}$ jump over the skin, Ljubljana, Slovenia. pp. 73-97.

5. Bajželj U, Kortnik J (2001) Technical aspects of the use of waste materials in mining. Proceedings of the $37^{\text {th }}$ Jump Across the Skin, Ljubljana, Slovenia. p. 13.

6. Kortnik J (2003) Backfilling waste material composites environmental impact assessment. Journal of the South African Institute of Mining and Metallurgy 103(6): 391-396. 